\title{
Febrile infection-related epilepsy syndrome
}

INSERM

\section{Source}

INSERM. (1999). Orphanet: an online rare disease and orphan drug data base. Febrile infection-related epilepsy syndrome. ORPHA:163703

Febrile infection-related epilepsy syndrome (FIRES) describes an explosive-onset, potentially fatal acute epileptic encephalopathy that develops in previously healthy children and adolescents following the onset of a non-specific febrile illness. 